\title{
OCUPAÇÕES E REOCUPAÇÕES POR GRUPOS PRETÉRITOS NO LITORAL CEARENSE: Os Vestígios Arqueológicos das Dunas de Trairi, Ceará, Brasil
}

\author{
Allysson Allan de Farias ${ }^{1}$ \\ Carlos Rios $^{2}$ \\ Daline Lima de Oliveira ${ }^{3}$ \\ Valdeci dos Santos Júnior ${ }^{4}$
}

\section{RESUMO}

Os sítios arqueológicos em sistemas dunares do Nordeste do Brasil têm sido pesquisados com mais intensidade nas últimas décadas nos Estados do Ceará, Rio Grande do Norte e Piauí. No município de Trairi-CE foi possível resgatar evidências culturais em superfícies dunares fixas de dois sítios arqueológicos que tiveram intervenções arqueológicas para obtenção de dados tipológicos e datações. Nas datações obtidas foi possível identificar a presença de grupos humanos naquele sistema dunar desde $3.460 \mathrm{BP}$, em vestígios de carvão associados à lascamentos antrópicos em silexito. As informações obtidas apontam, também, para ocupações e reocupações por grupos ceramistas nos dois sítios arqueológicos entre 1.790 BP e 900 BP, podendo ter chegado até o período colonial, quando a população pretérita, de menos de 500 anos, sobrevivia, baseado nos vestígios históricos e restos malacológicos localizados, de diversas fontes alimentares.

\footnotetext{
${ }^{1}$ Discente, Programa de Pós-graduação em Biologia Evolutiva, USP.

${ }^{2}$ Departamento de Arqueologia, UFPE.

${ }^{3}$ Discente, Programa de Graduação em Arqueologia, UNIVASF.

${ }^{4}$ Departamento de História, UERN.
} 
PALAVRAS CHAVES: Arqueologia dunar, padrões de assentamentos, zooarqueologia.

\section{ABSTRACT}

The archaeological sites in dune systems of northeastern Brazil have been researched more intensively in recent decades in the states of Ceará, Rio Grande do Norte and Piauí. In the municipality of Trairi, state of Ceará, it was possible to rescue cultural evidences in fixed dune surfaces of two archaeological sites which had archaeological work to obtain typological and dating information. Concerning the ages obtained, it was possible to identify the presence of human groups in this dune system since 3.460 BP with traces of anthropic chipping in silexito. The information obtained also indicate occupations and reoccupations by ceramist groups in both archaeological sites between $1.790 \mathrm{BP}$ and $900 \mathrm{BP}$, may have come to the colonial period when the preterit population of less than 500 years survived through various sources of food, based on historical and malacological remains.

KEY WORDS: Archaeological dune, settlement patterns, zooarchaeology.

Os estudos dos processos de formação dos vestígios culturais em sítios arqueológicos dunares no Brasil não é uma tarefa simples, pois características relacionadas à estrutura estratigráfica de tais ambientes são orientadas por mudanças constantes, graduais e, por vezes, de forma abrupta do solo, 
transformando totalmente os elementos da paisagem em poucos dias ou meses. Alguns desses elementos podem se apresentar como corpos d'água (rios e maceiós) ou por características topográficas como a altura das dunas móveis e fixas que, em geral, podem modificar os vestígios arqueológicos, carreando os materiais recentes para junto de materiais antigos em diferentes estratigrafias ou mesmo deformando-os pela ação de agentes tafonômicos abióticos.

De acordo com a dinâmica das dunas também é difícil elencar um conjunto de parâmetros para estudar a tafonomia em relação a abrigos rochosos e assentamentos e, desta forma, o estudo de tal ambiente arqueológico se torna difícil para responder questões relacionadas ao processo de formação do registro arqueológico (SCHIFFER, 1972).

As interpretações sobre os sítios arqueológicos em dunas no Brasil, geralmente, recaem sobre trabalhos relacionados à interpretação de elementos culturais de populações que viveram nas dunas da Bahia (ETCHEVARNE, 1991) ou sobre a caracterização de paleoambientes, com a presença de remanescentes de conchas de moluscos e cerâmica (WAGNER, 2011; TENÓRIO, 1998). Em relação ao Nordeste brasileiro, nos Estados do Ceará, Rio Grande do Norte e Piauí, também é possível observar, nas últimas décadas, algumas pesquisas científicas sobre o material arqueológico coletados em sítios dunares (NOBRE, 2013; MARQUES, 2011; SOUSA, 2011; BORGES, 2010, 2006; VIANA; SOUSA; SOARES, 2007; ALBUQUERQUE; SPENCER, 1994).

Devido à força e constância dos ventos da região litorânea do Estado do Ceará, a área tem sido estudada como promissora para instalação de usinas para geração de 
energia eólica. Esta potencialidade tem atraído diversas empresas para região no sentido de desenvolver econômica e socialmente toda a área do litoral cearense, além de fornecer energia elétrica para a população que ali reside (SILVA, 2005; BROWN, 2011).

Em conformidade com as resoluções e portarias do IPHAN (Portarias 07/1988, 230/2002 e a Instrução Normativa 01/2015) que regulamentam a ação direta ou indireta do patrimônio arqueológico, a construção de usinas eólicas tem sido acompanhada por profissionais da arqueologia. Tais ações preventivas visam preservar e/ou resgatar parte do conhecimento sobre os grupos humanos pretéritos, que ocuparam a faixa litorânea cearense em períodos cronológicos diferenciados. Desta forma foram realizados diagnósticos arqueológicos que apontaram uma quantidade de sítios catalogados no município de Trairi- $\mathrm{CE}^{5}$ que, até o final de 2014, apresentava 19 (dezenove) sítios arqueológicos dunares ${ }^{6}$, onde foi possível visualizar a presença predominante de vestígios cerâmicos e líticos.

Um desses sítios arqueológicos foi intitulado como São Jorge 1, que foi dividido em três setores denominados A,B e C, que fez parte de um conjunto de sítios resgatados no perímetro interno do Parque da Central de Geração Eólica São Jorge, no ano de 2013 (figura 1).

\footnotetext{
${ }^{5} \mathrm{O}$ município dista aproximadamente 130 quilômetros (direção NW) de Fortaleza, capital do Ceará.

${ }^{6}$ Números oficiais da base de dados do sistema de gerenciamento do patrimônio arqueológico CNSA- IPHAN, referente ao município de Trairi-CE.
} 


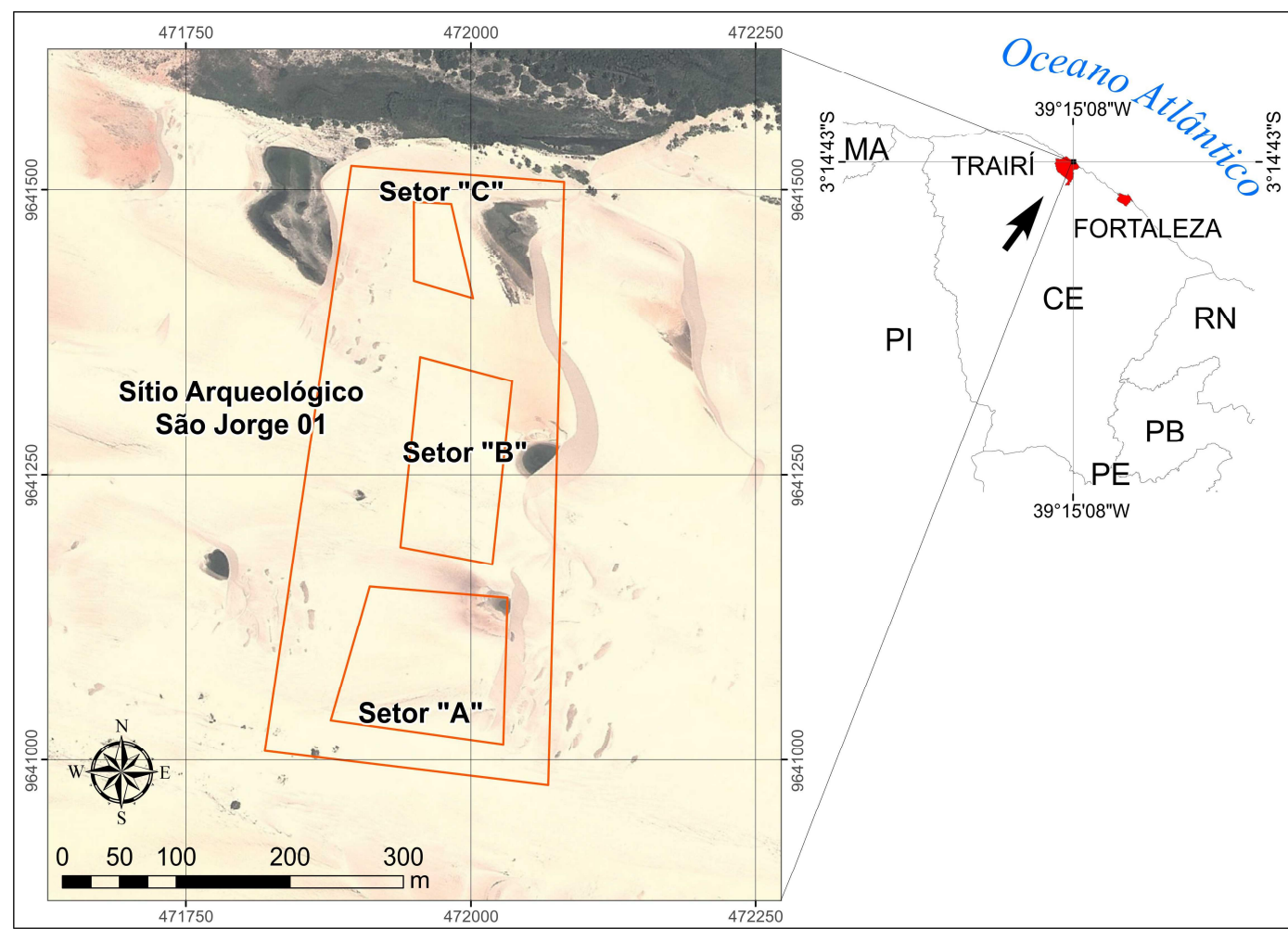

Figura 1: Imagem de localização do perímetro da CGE São Jorge e do Sítio Arqueológico São Jorge 1 (com os setores A, B e C) - Município de Trairi-CE. Fonte: Daniel Kim, 2013.

No perímetro interno desse sítio arqueológico, com dimensões de $514 \mathrm{~m}$ de comprimento por $250 \mathrm{~m}$ de largura, com cotas altimétricas variando entre $16 \mathrm{~m}$ (mais baixa) e $39 \mathrm{~m}$ (mais alta), foi possível observar vestígios faunísticos, cerâmicos, metálicos, vítreos e líticos agrupados em espaços distintos sobre a superfície de depressões dunares que foram, provavelmente, escolhidos por populações pretéritas para desenvolverem práticas cotidianas. 
Tais práticas estão ligadas a interpretação do passado a partir da análise tecnológica de ferramentas líticas que foram usadas por antigos habitantes da região, da tipologia cerâmica, de utensílios domésticos e da identificação de vestígios ósseos de animais que podem ter servido como alimentações para aquelas populações pretéritas.

Considerando o caráter exploratório da pesquisa, os objetivos deste artigo são descrever a tipologia e/datações dos vestígios arqueológicos localizados no São Jorge 1 e os vestígios zooarqueológicos encontrados em superfície fixa dunar, tentando interpretar o uso de tais vestígios orgânicos com base no aporte teórico da arqueologia comportamental e verificar a periodicidade da exposição dos vestígios arqueológicos.

Com o objetivo de efetuar correlações temporais com outros sítios arqueológicos próximos, foi efetuada também uma análise cronoestratigráfica de escavação efetuada em outro sítio arqueológico, intitulado Santo Antônio de Pádua 2, também situado em parque eólico próximo ao sítio arqueológico São Jorge 1.

\section{MATERIAIS E MÉTODOS}

O resgate dos vestígios líticos, cerâmicos, metálicos e vítreos do sítio se deu por meio da coleta de dados do registro arqueológico, a partir de três procedimentos metodológicos: a) Levantamento topográfico e delimitação da área de ocorrência de artefatos e demais vestígios de atividade humana pretérita com a utilização de Estação Total; b) Coleta sistemática de cultura material por meio de plotagem 
individual com Estação Total; c) Escavação de unidades de quadrículas de iguais dimensões (conjuntos de quadrículas e trincheiras).

Com relação à presença de material faunístico, em dois dos setores (A e B) foram escolhidos locais com dimensões de $1 \mathrm{~m}^{2}$ para quantificação de material orgânico em superfície. A escolha desta metodologia foi baseada no valor humanístico e científico do material e da técnica de reconhecimento superficial sistemático (DUNNELL e DANCEY, 1983; DUNNELL, 1984).

Para delimitação da área do sítio arqueológico em Setores A, B e C foi utilizado o dispositivo GPS do aparelho Nexus7(Asus), Datum WGS 84, para medição da precisão do GPS foi utilizado o aplicativo "GPS Test" (Chartcrosslimited) e para delimitação da área foi utilizado o aplicativo "Minhas trilhas" (Google inc.). A área foi calculada com auxílio do Google Earth Pro (Google inc.).

Durante o reconhecimento superficial, dois setores (A e B) apresentaram concentrações expressivas de vestígios zooarqueológicos, em relação ao setor C. A precisão do GPS foi de $4 \mathrm{~m}$. A metodologia da análise da dinâmica dunar através de imagens de satélite já foi feita por Sparavigna, em 2013, que empregou o método de superposição de imagens.

Durante o período de 26 a 28 de agosto de 2013 foram realizados reconhecimentos superficiais sistemáticos nos dois setores (A e B) do sítio arqueológico São Jorge 1. A metodologia empregada foi a quantificação do material de superfície, de forma aleatória, em um setor com $1 \mathrm{~m}^{2}$. Ao todo foram 
observados dois setores para esta quantificação: um no centro do Setor A e um no centro do Setor B.

O Setor A, visualmente, apresentou certa concentração de ossos e o local escolhido foi localizado na interseção entre as partes de maior e a de menor ocorrência; Já o Setor B apresentava ossos com concentração uniformemente expressiva em toda área. Os ossos foram quantificados conforme protocolo de Marshal e Pilgram (1993), a partir do qual, foram extraídas informações sobre o Número Mínimo de Espécimes Identificados (NISP), o Mínimo Número de Elementos (MNE) e o Mínimo Número de Indivíduos (MNI). Para quantificação foram utilizadas também as sugestões de Dominguez-Rodrigo (2012).

A identificação dos gastrópodes foi baseada na chave de Simone (2006), levando em consideração a morfologia da concha; incluindo altura e formato da espira, formato da abertura da concha.

\section{RESULTADOS}

Foi coletado nos três setores (A, B e C) do sítio arqueológico São Jorge 12.792 vestígios arqueológicos e 24 restos malacológicos (tabela 1): 


\begin{tabular}{|c|c|c|c|}
\hline VESTÍGIOS & SETOR A & SETOR B & SETOR C \\
\hline Artefatos líticos (quartzo) & 0294 & 0266 & 0082 \\
\hline Artefatos líticos (sílex) & 0095 & 0095 & 0021 \\
\hline Artefatos cerâmicos & 1247 & 0214 & 0052 \\
\hline Artefatos cerâmicos (grés) & 0020 & - & - \\
\hline Restos de carapaças de gastrópodes & 0010 & 0006 & - \\
\hline Restos ósseos não identificados & 0007 & - & - \\
\hline Fragmentos de artefatos (granito) & 0003 & 0002 & - \\
\hline Artefato em metal (botões) & 0002 & 0001 & - \\
\hline Artefato em metal (medalha) & 0001 & - & - \\
\hline $\begin{array}{l}\text { Fragmentos de artefatos em faiança } \\
\text { fina }\end{array}$ & 0352 & - & 0001 \\
\hline Artefatos em metal não identificados & 0021 & - & - \\
\hline Artefato polido ( lâmina de machado) & 0002 & - & - \\
\hline Projéteis em metal & 0001 & - & - \\
\hline Fragmentos de artefatos em vidro & 0014 & - & - \\
\hline Artefato em metal (dedal) & 0005 & - & - \\
\hline Fragmento de adorno (amazonita) & - & - & 0001 \\
\hline Fragmento de carvão & - & 0001 & - \\
\hline Total & 2074 & 0585 & 0157 \\
\hline TOTAL GERAL & \multicolumn{3}{|c|}{2816} \\
\hline
\end{tabular}

Tabela 1: Cultura material e malacológica resgatada no Sítio Arqueológico São Jorge 1, Município de Trairi - C, Fonte: Santos Júnior, 2013. 


\subsection{Vestígios Líticos}

Nos três setores do sítio São Jorge 1 foram coletados 860 artefatos, derivados de atividades de lascamento. A matéria-prima utilizada em maior número foi o quartzo (75\%), vindo em seguida o silexito (25\%). A maior parte dos vestígios eram restos de debitagem, mas foram observados também instrumentos sobre seixos de quartzo, assim como lascas corticais e semicorticais em quartzo. A predominância quase absoluta era de material lascado, vindo em menor número o material polido (07 peças).

\subsection{Vestígios Cerâmicos}

A análise dos vestígios cerâmicos coletados se limitou à identificação do tipo de pasta, às técnicas de manufatura e do tratamento de superfície. Quanto à pasta foram identificados três tipos: a pasta 1 apresentava areia quartzosa como tempero, não possuindo vazios nem bolhas de ar, sendo bem homogênea; a pasta 2 apresentava bolhas de ar, sendo pouco homogênea e apresentando areia de quartzo como tempero; a pasta 3 apresentava areia e grânulos de quartzo, cacos triturados e bolos de argila.

Foram identificados os três tipos de pastas cerâmicas nos três setores do sítio, embora a predominância seja a do tipo 2 que apresenta uma maior frequência em termos de antiplástico com grãos de quartzo. As técnicas de manufatura utilizadas foram a acordelada e torneada. A princípio (haja vista que ainda não foram 
efetuadas datações dos fragmentos) é possível que exista uma mistura temporal envolvendo fragmentos cerâmicos com características históricas e pré-históricas.

Vestígios de cerâmicas vitrificadas do período histórico representadas por exemplares de grés e faiança fina foram encontradas, associados com os demais fragmentos cerâmicos mencionados. A predominância de tais vestígios históricos estava localizada no Setor A, vindo em menor número no Setor B e quase inexistente no Setor C.

\subsection{Demais Vestígios Culturais}

Foram identificados também outros vestígios culturais, tais como, metais (pregos, colheres, medalha religiosa do século XIX, botões de vestuários e dedais), fragmentos vítreos (restos de garrafas) e 01 adorno em amazonita.

Foram coletados 02 projetis metálicos: o primeiro projétil era pertinente a fuzil de calibre 7.62 mm (utilizado em armas AK 47; FN SC SCAR; HK 416/417 e FN FAL), encamisado (com cobertura de cobre sobre a massa de chumbo), pesando 7,9783 gramas, com desgaste provocado pelo tempo de exposição na duna, formando pequenas concavidades no corpo do projetil, fruto da ação eólica. Esse tipo de projétil existe desde a década de 1940. O segundo projetil é pertinente a revólver calibre 32 podendo, quando encamisado, guarnecer pistolas 7.65, pesando 9,325 gramas, existente desde 1878 e em pistolas desde 1889 . 


\subsection{Vestígios Zooarqueológicos}

De acordo com o "Livro Vermelho" publicado pelo Instituto Chico Mendes em 2008, a pequena fauna da região litorânea cearense apresenta mais de cinquenta espécies de animais ameaçados de extinção.

Dois setores (A e B) do sítio apresentavam vestígios faunísticos relativos a espécies de mamíferos de médio porte, ungulados, aves, micromamíferos, moluscos, além de estruturas que remetem a usos diversos desses materiais, como ossos queimados, pintados, com perfuração por materiais ferrosos e vasos com marcas de descarne.

De modo geral, o setor A apresentou uma quantidade diversa de espécies e indivíduos espalhados em uma área de 1 metro quadrado. Tanto gastrópodes, quanto ossos de mamíferos de pequeno e grande porte, vértebras e presas. Foi observada também a presença de ossos de aves e fragmentos de carvão.

Por outro lado, o setor $\mathrm{B}$, apresentou somente conchas de gastrópodes e fragmentos de carvão. A quantificação (tabela 02) resultou em, no mínimo, 3 gastrópodes, 3 roedores, 2 suínos, 2 canídeos, 4 aves, 4 caprinos e 1 angiosperma no setor A; e 12 gastrópodes no setor B. No entorno dos dois setores existem fragmentos ósseos diversos. 
Clio Arqueológica 2016, V31N1, pp. 53-80, FARIAS; RIOS; OLIVEIRA; JÚNIOR DOI: 10.20891/clio.v31i1p53-80

\begin{tabular}{|c|c|c|c|c|}
\hline \multirow{2}{*}{\multicolumn{2}{|c|}{ Número de fragmentos $(\mathrm{N})$}} & NISP & MNI & MNE \\
\hline & & \multicolumn{3}{|c|}{ Setor A } \\
\hline Gastrópodes & & 3 & 3 & 3 \\
\hline \multirow{3}{*}{ Caprino } & Osso Longo & 18 & 4 & 18 \\
\hline & Queimados & 7 & 1 & $?$ \\
\hline & Costela & 7 & 3 & 7 \\
\hline Aves & Escápula & 10 & 4 & 10 \\
\hline Canídeo & Presa & 5 & 2 & \multirow{2}{*}{9} \\
\hline Suíno & Presa & 4 & 2 & \\
\hline \multirow{4}{*}{ Roedor } & Mandíbula & 9 & 1 & 9 \\
\hline & Fêmur & 4 & 3 & 4 \\
\hline & Tíbia & 2 & 1 & 2 \\
\hline & Vértebras & 5 & 3 & 5 \\
\hline \multirow[t]{2}{*}{ Angiosperma } & Carvão & 11 & 1 & 11 \\
\hline & & \multicolumn{3}{|c|}{ Setor B } \\
\hline \multirow{3}{*}{ Gastrópodes } & Pyramidellidae & 4 & 4 & 4 \\
\hline & \begin{tabular}{|l} 
Helicinidae \\
\end{tabular} & 7 & 7 & 7 \\
\hline & Columbellidae & 1 & 1 & 1 \\
\hline Angiosperma & Carvão & 78 & 1 & 78 \\
\hline
\end{tabular}

Tabela 2 - Quantificação dos vestígios ósseos localizados nos setores A e B do sítio Arqueológico São Jorge 1, fonte: Farias, 2013.

Considerando uma interpretação bioantropológica para os vestígios ósseos, o setor A pode ter servido como área de alimentação das populações ali viventes, tendo 
em vista a presença de ossos queimados na mesma superfície onde foram encontrados fragmentos de carvões.

Ainda naquele setor, têm-se marcas de perfuração por lascas em ossos de mamíferos, o que aumenta a hipótese de uso do sítio arqueológico como local de alimentação. Há um visível padrão de escolha do local delimitado devido à abundância de conchas de gastrópodes e ferramentas líticas.

Já no setor B foram localizados, basicamente, remanescentes calcificados de origem marinha composta por espécies distintas de gastrópodes marinhos, provavelmente das famílias Columbellidae, Pyramidellidae e Helicinidae.

\subsection{Intervenções Arqueológicas e Datações no Sítio Arqueológico São Jorge 1}

A partir da análise da distribuição espacial, cotas altimétricas, da tipologia e das concentrações de vestígios arqueológicos em superfície do sítio arqueológico São Jorge 1, foram realizadas 03 sondagens arqueológicas no setor A (vide exemplo de sondagem na figura 02), 03 sondagens arqueológicas no Setor B e 03 sondagens arqueológicas no Setor $\mathrm{C}$, com dimensões e profundidades variáveis ${ }^{7}$, que teve, como objetivo, observar a dinâmica de deposição sedimentar e os processos de formação do registro arqueológico.

\footnotetext{
${ }^{7}$ As dimensões das sondagens variaram entre $5 \times 1 \mathrm{~m}$ a $10 \times 10 \mathrm{~m}$; O nível de profundidade variou de acordo com as camadas sedimentares, tendo sondagens com $10 \mathrm{~cm}$ até $150 \mathrm{~cm}$.
} 


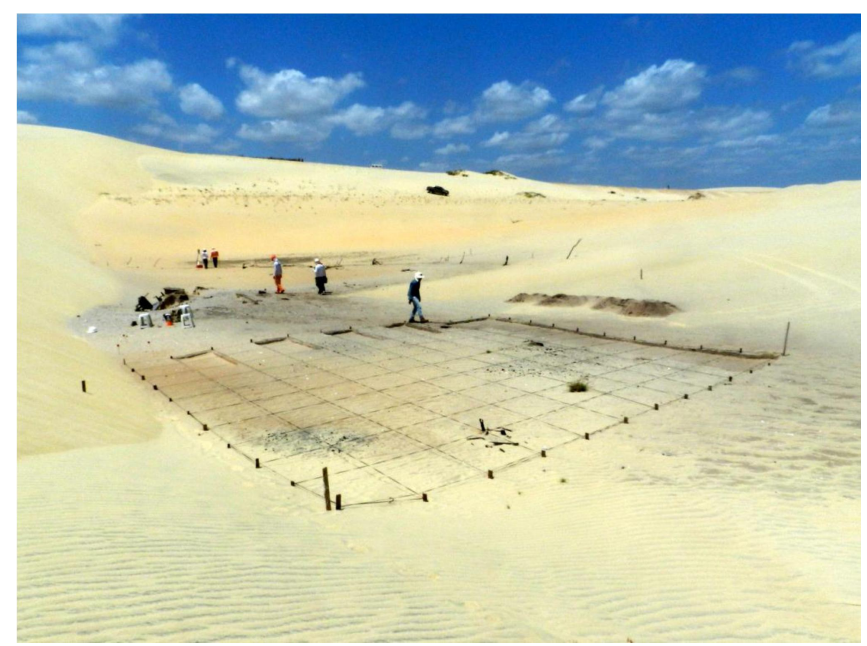

Figura 2: Visão da sondagem 1 realizada no Setor A - Sítio Arqueológico São Jorge 1 - Município de Trairi-CE, fonte: Santos Júnior, 2013.

Na sondagem 01 do Setor A foi coletada uma amostra oriunda de fragmentos de carvão para datação em níveis estratigráficos $(40 \mathrm{~cm})$ no mesmo nível sedimentar contendo material lítico no sítio São Jorge 01. A amostra sedimentar (Beta 382676) foi enviado ao laboratório Beta Analitic, de Miami, EUA, que com a utilização do método da Espectrometria de Massas com Aceleradores (AMS) foi possível obter a datação de 1.790 BP com margem de erro de 30 anos.

\subsection{Intervenções Arqueológicas e Datações no Sítio Arqueológico Santo}

\section{Antônio se Pádua 2}

Na central de geração eólica Santo Antônio de Pádua (anexa a central de geração eólica São Jorge), foram resgatados vestígios culturais de 3 sítios arqueológicos, 
intitulados Santo Antônio de Pádua 1, Santo Antônio de Pádua 2 e Santo Antônio de Pádua 3.

A predominância dos vestígios arqueológicos em nível de superfície no sítio Santo Antônio de Pádua 2 possuía características tipológicas aparentemente de cunho pré-histórico composto por material lítico e cerâmico, além de vestígios inequívocos (faiança, vidros, metais) do período histórico. Foram coletados em nível de superfície 1.949 líticos (com matérias-primas em quartzo, silexito, arenito e granito), sendo 1.911 líticos em nível de superfície e 38 líticos em nível de subsuperfície. Para observação de possíveis vestígios em nível de subsuperfície, foram realizadas 08 sondagens arqueológicas com dimensões diferenciadas. Em 5 sondagens foram localizados 38 vestígios líticos em nível de subsuperfície. 1 lítico na sondagem 1; 3 líticos na sondagem 3; 18 líticos na sondagem 4; 5 líticos na sondagem 5 e 11 líticos na sondagem 06 .

A sondagem 4 teve dimensões de $10 \mathrm{~m} \times 2 \mathrm{~m}$, sendo realizada em uma área com cota altimétrica de $41 \mathrm{~m}$ e localizada na meia encosta de uma elevação dunar semifixa, onde aparecem sedimentos arenosos do Quaternário. O objetivo era averiguar um possível deslocamento do material arqueológico vindo da parte mais elevada da ravina devido à ação da gravidade. Foram identificados 18 vestígios líticos (quartzo e silexito) em nível de subsuperfície com a seguinte distribuição no perfil estratigráfico (tabela 03 ). 


\begin{tabular}{|c|c|c|c|}
\hline Decapagem & Profundidade- $\mathrm{cm}$ & Quadrícula & Vestígio arqueológico \\
\hline \multirow[b]{2}{*}{01} & \multirow[b]{2}{*}{$0-10$} & b1 & 01 núcleo em silexito \\
\hline & & c1 & 01 lasca em silexito \\
\hline & & & 01 fragmento em granito \\
\hline 02 & $10-20$ & c1 & 01 núcleo em quartzo \\
\hline \multirow{3}{*}{03} & \multirow{3}{*}{$20-30$} & a1 & 01 resíduo em quartzo \\
\hline & & $\mathrm{c} 1$ & 01 instrumento em quartzo \\
\hline & & d1 & 01 lasca em quartzo \\
\hline \multirow{3}{*}{04} & \multirow{3}{*}{$30-40$} & a1 & 01 lasca em quartzo \\
\hline & & $\mathrm{c} 1$ & 01 lasca em quartzo \\
\hline & & $\mathrm{d} 1$ & 01 lasca em silexito \\
\hline 05 & $40-50$ & d1 & 01 instrumento em quartzo \\
\hline 06 & $50-60$ & - & - \\
\hline 07 & $60-70$ & - & - \\
\hline 08 & $70-80$ & - & - \\
\hline 09 & $80-90$ & - & - \\
\hline 10 & $90-100$ & g1 & 02 instrumentos em quartzo \\
\hline \multirow[t]{2}{*}{11} & \multirow[t]{2}{*}{$100-110$} & \multirow[t]{2}{*}{ j1 } & 01 lasca em silexito \\
\hline & & & 01 lasca em quartzo \\
\hline 12 & $110-120$ & j1 & 01 lasca em silexito \\
\hline 13 & $120-130$ & - & - \\
\hline 14 & $130-140$ & - & - \\
\hline 15 & $140-150$ & $\mathrm{j} 1$ & 02 lascas em silexito \\
\hline
\end{tabular}

Tabela 3 - Perfil estratigráfico vertical com distribuição do material arqueológico localizado durante as decapagens na sondagem 4 - Sítio Arqueológico Santo Antônio de Pádua 2 - Município de Trairi - CE, fonte: Santos Júnior, 2013. 
A sondagem 4 estava localizada nas coordenadas 24M 0475415 E $9638011 \mathrm{~N}$ (Datum WGS 84), sendo efetuadas 15 decapagens que atingiram até a profundidade de $150 \mathrm{~cm}$, sendo possível observar 3 momentos temporais de deposição/formação do registro arqueológico:

a) O primeiro momento temporal está situado no intervalo espacial do nível de superfície até a $5^{\text {a }}$ decapagem $(40-50 \mathrm{~cm})$, onde foi possível observar a presença constante de vestígios líticos com alternâncias de lascas, núcleos e instrumentos em quartzo (predominância), silexito e granito (de forma intrusiva);

b) $\mathrm{O}$ momento seguinte está compreendido entre a 6 e a 9 decapagem $(50 \mathrm{~cm}$ a $90 \mathrm{~cm}$ ), onde ocorre um hiato com a total inexistência deposicional de vestígio cultural;

c) O último momento temporal está compreendido entre as decapagens $10 \mathrm{e}$ 15 (entre $100 \mathrm{~cm}$ até $150 \mathrm{~cm}$ ), onde volta a ser observada a presença de vestígios líticos (em quartzo e silexito) com lascas, instrumentos e resíduos de debitagem.

A coleta para datação ocorreu nos 3 intervalos temporais, sendo uma primeira

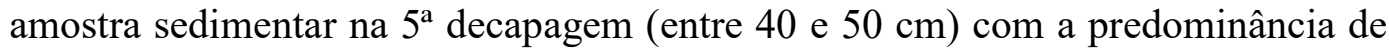
sedimentos arenosos (com alternâncias de tonalidades esbranquiçadas e suaves tonalidades da cor vermelha) do Quaternário.

Uma segunda amostra na $9^{\text {a }}$ decapagem (entre $80-90 \mathrm{~cm}$ ) quando finaliza os sedimentos arenosos de tonalidade esbranquiçada e tem início um pacote sedimentar com material terrígeno avermelhado (provavelmente por influência do óxido de ferro) do Quaternário e a presença de vestígios líticos a partir de $100 \mathrm{~cm}$. 
Finalmente, uma terceira amostra no mais baixo nível estratigráfico, ou seja, na $15^{\mathrm{a}}$ decapagem (140 a $150 \mathrm{~cm}$ ), onde ainda apareceram vestígios líticos (2 lascas em silexito) com a predominância de sedimentos arenosos avermelhados do Quaternário (figuras 3 a 5).
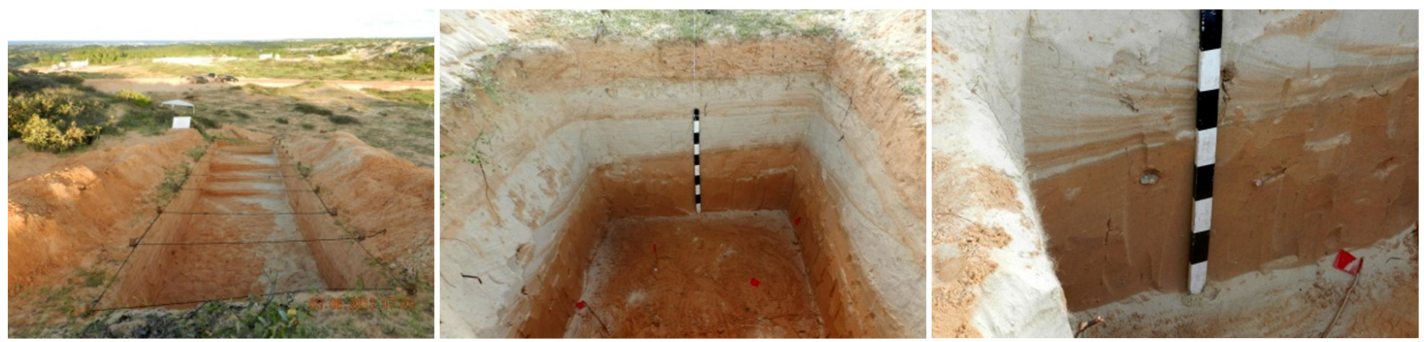

Figura 3: Contexto Figura 4: Perfil Figura 5: Vestígios líticos geoambiental da estratigráfico da sondagem até $150 \mathrm{~cm}$ no perfil sondagem 4 - Sítio 4 - Sítio Arqueológico estratigráfico da sondagem Arqueológico Santo Santo Antônio de Pádua 24 - Sítio Arqueológico Antônio de Pádua 2 - - Trairi-CE. Trairi-CE. Santo Antônio de Pádua 2 - Trairi-CE.

As três amostras sedimentares (Beta - 382677, Beta - 382679 e Beta - 382680) também foram enviadas ao laboratório Beta Analitic, de Miami, EUA, cuja utilização do método da Espectrometria de Massas com Aceleradores (AMS) obteve a seguinte cronologia (tabela 04 ): 


\begin{tabular}{|c|c|c|c|c|}
\hline Número da amostra & Sondagem & Decapagem & Profundidade & Datação - BP \\
\hline 1 & 4 & 5 & $40-50 \mathrm{~cm}$ & $1.690+/-30$ \\
\hline 2 & 4 & 9 & $80-90 \mathrm{~cm}$ & $3.010+/-30$ \\
\hline 3 & 4 & 15 & $140-150 \mathrm{~cm}$ & $3.460+/-30$ \\
\hline
\end{tabular}

Tabela 4 - Quadro de datações da sondagem 4 - Sítio Santo Antônio de Pádua 2 - Município de Trairi - CE, fonte: Santos Júnior, 2013. Datações (laboratório Beta Analitic, Miami, EUA).

\section{DISCUSSÃO}

Os resultados obtidos nas intervenções arqueológicas realizadas nos sítios São Jorge 1 e Santo Antônio de Pádua 2 permitiram levantar algumas inferências sobre os processos de formação do registro arqueológico naquele sistema dunar existente no município de Trairi-CE.

\subsection{Sistema Dunar/Vestígios Ósseos}

A estrutura do sistema dunar de Trairi é igual à estrutura exposta por Tsoar et al. (2009), apresentando dunas brancas e dunas vermelhas por conta da deposição de Fe; as dunas estabilizadas, que são geralmente de tons vermelhos e alaranjados, foram testemunhas de eventos de glaciação ao longo dos últimos 130 mil anos. A velocidade de avanço das dunas na região, em média 15 metros por ano, também é parecida com a velocidade de avanço estudadas por Jimenez et al.(1999), que foi de $17,5 \mathrm{~m}$ por ano.

Baseado nas estruturas históricas encontradas, bem como partindo do princípio que os ossos encontrados foram descarnados e queimados, é possível sugerir que a 
população pretérita de menos de 500 anos, se alimentava de diversas fontes. Neste sentido, eles comiam alimentos ricos em proteína e ômega-3, fazendo com que houvesse proteção para o cérebro e manutenção dos sistemas biológicos (DOMINGO E BÓCIO, 2007), portanto quanto ao Sítio arqueológico São Jorge 1, o Setor A é um local de alimentação generalista e o Setor B apresenta espécies ligadas à alimentação voltada aos gastrópodes marinhos, embora fossem encontrados ossos de ungulados de forma esparsa.

Em tal cenário de contato, foi possível observar também anzóis de osso e estruturas metálicas diversas, que podem ter servido para pesca de peixes e outros animais marinhos. Devido à localização de o sítio arqueológico dunar estar próximo de recifes de arenito, o hábito da coleta durante a maré baixa deve ter sido muito utilizado. Desta forma é plausível argumentar que os nativos daquela região tiveram nos ambientes costeiro-estuarino, próximo as dunas, rico material para nutrição, além de uso de metais (decorrente de possível contato com colonizadores), embora o descarne indique uso de lascas de silexito como agente tafonômico de marcas post-mortem relacionadas à Formação do Registro Arqueológico por características culturais (SCHIFFER, 1972).

\subsection{Datações Obtidas}

A princípio, as datações com retroatividade cronológica superior a três milênios de presença humana, envolvendo material lítico, em sítios dunares cearenses, podem suscitar questionamentos típicos da discussão científica pela própria 
fragilidade da estratigrafia em dunas. Nada mais salutar e natural. Entretanto, é possível levantar algumas ponderações.

A quantidade de sítios arqueológicos, assim como as pesquisas arqueológicas de cunho acadêmico, com datações cronológicas no Ceará ainda é ínfima e normalmente envolvem vestígios cerâmicos. $\mathrm{Na}$ base de dados do sistema de gerenciamento arqueológico do IPHAN (CNSA) consta a existência de 535 sítios arqueológicos e talvez, somente, entre 4 a 5 deles tenham sido alvo de datações diretas e/ou indiretas, como se observa em alguns casos:

a) No sítio Sabiaguaba 2, localizado na praia de Sabiaguaba, em Fortaleza, foi obtida uma datação de $4.600 \pm 30 \mathrm{BP}$ (SOUSA, 2011). Na área da bacia hidrográfica do rio Curu, município de São Gonçalo do Amarante, foi identificada a presença de grupos pré-históricos há, pelo menos, 4.580 \pm 30 BP através de fragmentos de carvões de uma fogueira encontrada a 80 centímetros de profundidade no sítio arqueológico Caiçara. ${ }^{8}$

b) Na Praia de Jericoacoara, um acervo ceramista do horizonte cultural designado "Papeba" foi datado em 1.200 BP.

\footnotetext{
${ }^{8}$ O sítio Caiçara apresenta outras três ocupações também datadas em $3.400 \pm 30$ anos AP, $3.290 \pm$ 30 anos AP e $980 \pm 30$ anos AP, respectivamente. A hipótese levantada até o momento é de que o sítio tenha sido ocupado por um grupo de caçadores-coletores-pescadores por volta de 4.580 anos AP, por um grupo de caçadores-coletores-pescadores-ceramistas entre 3.290 e 3.400 anos AP, e por um grupo de horticultores ceramistas da tradição Tupiguarani por volta de 980 anos AP (Instituto Cobra Azul. Acessado http://cobrazul.com.br/arqueologos-ceara/ em 14.01.2016).
} 
Neste contexto, já foi confirmada a presença humana no RN, há $4.150 \mathrm{BP}$, em área situada a pouco menos de $45 \mathrm{~km}$ da costa litorânea, com atividades predominantemente voltadas para lascamentos antrópicos em silexito (SANTOS JÚNIOR, 2013).

Sítios litorâneos dunares, assim como sambaquis apresentam, frequentemente, datações entre 8.000 e $2.000 \mathrm{BP}$, a maioria com datações entre 5.000e $3.000 \mathrm{BP}$ (PROUS, 1991). No litoral do vizinho estado do Piauí, no município de Luís Correia, há também evidência de populações indígenas na Praia da Carnaubinha, no sítio das Três Marias e sítio do Seu Bode, na Praia do Macapá, com alguns projetos de pesquisa com datações abrangendo um intervalo cronológico entre 400 a 2.700 BP (BORGES, 2006).

O que não se pode descartar, apesar da fragilidade da estratigrafia em sítios dunares, é a possibilidade efetiva de ocupações e reocupações de tais espaços ambientais por grupos pretéritos humanos (pré-históricos e históricos), em busca de alimentos marisqueiros situados próximos aos reservatórios naturais de águas das chuvas, como ocorre nas depressões dunares (conhecidas na região como lagoas naturais).

Por algum processo geológico sedimentar ainda não identificado, houve a mistura entre os sedimentos holocênicos por processos de deposição pertinentes à dinâmica dunar em tal espaço específico. Pode-se levantar a hipótese da presença humana nas dunas cearenses utilizando artefatos líticos desde 3.460 BP (Período Holocênico) compreendido pelas datações obtidas, salvo a interferência 
desconhecida de outros fatores naturais de perturbação sedimentar (como a percolação).

\section{CONCLUSÕES}

Os conjuntos artefatuais cerâmicos, líticos e malacológicos coletados no sítio arqueológico São Jorge 1 e as intervenções arqueológicas no sítio Santo Antônio de Pádua 2, apontam para eventos de ocupações e reocupações pretéritas com padrões de assentamentos de grupos ceramistas em dunas, em cronologias que podem retroagir a $1.790 \mathrm{BP}$.

Em tais sítios a deposição dos vestígios e artefatos nos locais onde foram desenvolvidas as atividades pretéritas, forneceu uma oportunidade de identificação das práticas econômicas relacionadas ao processamento de recursos do ambiente costeiro-estuarino, representado principalmente por carapaças de gastrópodes com marcas de uso e lascamento de rochas silicosas. Em razão da coincidência entre os locais de refugo e de atividade, os sítios parecem ser exemplo de ocupações de grupos numericamente pequenos, em eventos de ocupação rápida.

Além das ocupações mais recuadas (3.460 BP, 3.010 BP, 1.790 BP e 1.690 BP), duas ocupações mais recentes $(900 \mathrm{BP})$ se sucederam na área, inferência corroborada pelos grupos ceramistas que podem ter cronologias no Período do Contato, vindo também, em períodos mais recentes, muito provavelmente até fins do século XIX e inicio do século XX, onde podem ter ocorrido eventos de 
deposição de artefatos ou mesmo de ocupação sazonal nas áreas dos sítios ocupados pelos grupos indígenas. Tais sítios, ademais, documentam a adaptação de grupos ceramistas mais recentes ao ambiente costeiro, uma vez que eles passaram a ocupar áreas com características ambientais notadamente diversas de seus lugares de origem. No caso dos ceramistas da Tradição Tupiguarani, por exemplo, que alcançaram o litoral nordestino, em áreas onde as formações de caatinga e clima semiárido alcançam a zona costeira.

O conjunto destas variáveis ambientais daquele setor litorâneo levou tais grupos a apresentar a variante ocupacional na forma de um contexto específico de ocupação sazonal litorânea e, muito provavelmente, da fauna aquática estuarina e costeira. Os sítios são especialmente informativos, pois documentam principalmente o processo de adaptação de tais grupos ao litoral, uma vez que, em sua expansão pelo Nordeste, os Tupi já teriam ocupado as áreas de mata úmida (próximas da faixa litorânea) até as mais internas do semiárido.

\section{REFERÊNCIAS BIBLIOGRÁFICAS}

ALBUQUERQUE, P. T. S.; SPENCER, W. B. Projeto arqueológico - O Homem das dunas. Revista Clio. Série Arqueológica (UFPE), v. 1, p. 10-20, 1994.

BORGES, J. F. Os Senhores das Dunas e os Adventícios d'Além Mar: primeiros contatos, tentativas de colonização e autonomia Tremembé na Costa Leste-Oeste (séculos XVI e XVII). Tese (Doutorado em História). Rio de Janeiro: UFRJ, 2010.

Sob os areais: arqueologia, história e memória. Dissertação. (Mestrado em História) UFPI, Teresina, 2006. 
BROWN, K. B. Wind power in northeastern Brazil: Local burdens, regional benefits and growing opposition. Climate and development, 3(4):344-360, 2011.

DOMINGO, J. L.; BOCIO, A. Levels of PCDD/PCDFs and PCBs in edible marine species and human intake: A literature review. Environment International, 33(3):397-405, 2007.

DOMÍNGUEZ-RODRIGO, M. Critical review of the MNI (minimum number of individuals) as a zooarchaeological unit of quantification. Archaeological and anthropological Sciences, 4:47-59, 2012.

DUNNELL, R. C. The ethics of archaeological significance decisions. In: Green, E. L. (Ed.), Ethics and values in Archaeology. New York: Free Press, 1984.

DUNNELL, R. C.: DANCY, W.S. The siteless survey: a regional scale data collection strategy. Advances in Archaeological Method and Theory, 6: 267-287, 1983.

ETCHEVARNE, C. Sítios Dunares: contribuição à arqueologia do submédio São Francisco. Dissertação (Mestrado em Arqueologia), FFLCH-USP, 1991.

INSTITUTO COBRA AZUL, 2012. www.cobra.azul.com.br acessado em 02 de Fevereiro de 2016.

JIMENEZ, J. A.; MAIA, L. P.; SERRA, J.; MORAIS, J. Aerolian dune migration along the Ceará coast, northeastern Brazil. Sedimentology, 46:689-701, 1999.

MARQUES, M. Diagnóstico arqueológico na área das linhas de transmissão do complexo eólico Santos, em Trairi. Relatório Privado. Arquivos do IPHAN-CE, 2011.

MARSHALL, F.; PILGRAM, T. NISP vs. MNI in quantification of body-part representation. American Antiquity, 58(2), 261-269, 1993. 
MINISTÉRIO DO MEIO AMBIENTE. Livro vermelho da fauna brasileira ameaçada de extinção. Publicação do Instituto Chico Mendes e da Secretaria de Biodiversidade e Florestas.Brasília, 2008.

NOBRE, J. N. Memória social e espacialidade de grupos ceramistas em Trairi, CE. Dissertação (Mestrado em ?), UFPE, 2013.

PROUS, A. Arqueologia brasileira. Brasília: Editora Universidade de Brasília, 1991.

SIMONE, L. R. L. Land \&freshwater molluscs of Brazil. São Paulo: EBG, 2006.

TENÓRIO, M. C. Abandonment in Brazilian coastal sites: Why leave the Eden. In: Plew, M. G. (Org.). Explorations in American Archaeology: Essays in honor of Wesley Hurt. Maryland: University Press of America, 221-258, 1998.

TSOAR, H.; LEVIN, N.; PORAT, N.; MAIA, L. P.; HERMANN, H. J.; TATUMI, S. H.; CLAUDINO-SALES, $\mathrm{V}$. The effect of climate change on the mobility and stability of coastal sand dunes in Ceará state (NE Brazil). Quaternary Research, 71:217-226, 2009.

SANTOS JÚNIOR, V. Arqueologia da paisagem: proposta geoambiental de um modelo explicativo para os padrões de assentamentos no Enclave Arqueológico Granito Flores, microrregião de Angicos (RN). Tese (Doutorado em Arqueologia)- Programa de PósGraduação em Arqueologia, Universidade Federal de Pernambuco, 2013.

SCHIFFER, M.B. Archaeological context and systemic context. American Antiquity, 156-65, 1972.

SILVA, N. F.; ROSA, L. P.; ARAÚJO, M. R. The utilization of Wind energy in the Brazilian electric sector's expansion. Renewable and Sustainable Energy Reviews, 9(3):289-309, 2005. 
SOUSA, L. D. A. Os grupos pré-históricos ceramistas da praia de Sabiaguaba, Fortaleza/CE - Brasil. Dissertação (Mestrado em Arqueologia), Programa de PósGraduação em Arqueologia, UFPE, Recife, 2011.

SPARAVIGNA, A. C. A study of moving sand dunes by means of satellite images. The International Journal of Sciences, 2:33-42, 2013.

VIANA, V. P.; SOUSA, L. D.; SOARES, K. A. Os antigos habitantes da praia de Jericoacoara, Ceará: Arqueologia, História e Ambiente. Recife: Clio. Série Arqueológica (UFPE), n. 21, 2007.

WAGNER, G.; HILBERT, K.; BANDEIRA, D.; TENÓRIO, M. C.; OKOMURA, M. M. Sambaquis (shell mounds) of the Brazilian coast. Quaternary International, 239:51-60, 2011. 